\title{
Sistema médico kaingang: Conhecimentos e utilização de "remédios do mato" na Terra Indígena Apucarana
}

\author{
Eduardo Tardeli de Jesus Andrade*
}

\begin{abstract}
Resumo: Este trabalho busca compreender os sentidos e significados, atribuídos pelos Kaingang, de suas práticas ligadas aos processos de adoecer e curar, focalizando os conhecimentos e a utilização de "remédios do mato", venh kagta. É decorrente de pesquisa de campo realizada entre 2010 e 2011 na Terra Indígena (TI) Apucarana, localizada na cidade de Tamarana, no Paraná. As concepções e práticas de atenção à saúde Kaingang estão intimamente ligadas à sua cosmovisão e as relações que mantêm com a natureza, imersas em um contexto multi-étnico e de pluralismo médico, são constantemente criadas e recriadas de forma criativa pelos Kaingang.
\end{abstract}

Palavras-chave: Kaingang, cosmologia, saúde indígena, "remédios do mato".

\section{Concepção kaingang de saúde e doença: relação com a natureza e cosmologia}

A população Kaingang é uma das mais numerosas do Brasil, são mais de 30 mil índios que vivem em aldeamentos localizados nos três estados do Sul do país e no Estado de São Paulo. A língua Kaingang pertence à família Jê do tronco lingüístico macro-Jê, e juntamente com os índios Xokleng constituem os Jê Meridionais (SiLVA, 2002; Tommasino, 2004).

Os índios Kaingang não concebem o meio ambiente unicamente como fornecedor de matéria-prima, mas se veem como parte dele. Não o consideram inerte, ao contrário, para eles todos os elementos naturais são dotados de espírito, kuprim, e agem com intencionalidade (Tommasino, 2004).

Na visão cosmológica Kaingang, "tudo tem espírito", seja insetos, árvores, animais, pedras, montanhas, etc, (VeigA, 1994; Oliveira, 1996; RosA, 2005). Eles são grandes observadores dos ciclos naturais e têm enorme conhecimento dos seres que habitam a floresta, sendo suas relações com eles determinantes na manutenção de sua força, tar, ou de sua saúde.

A noção de força é central na concepção de saúde Kaingang, estar forte significa estar protegido de enfermidades e, por sua vez, estar fraco significa estar vulnerável a elas. Esta atribuição, forte e fraco, também é aplicada aos "remédios do

\footnotetext{
${ }^{*}$ Graduando em Ciências Sociais - UEL
} 
mato" ${ }^{1}$, venh kagta, uma vez que estes têm mais força que aqueles provenientes do posto de saúde. Os "remédios do mato" recebem um segundo atributo com relação ao local de que são provenientes. Aos venh kagta, portanto, que são provenientes da mata fechada, e os do quintal são atribuídos como remédios com mais e menos força, respectivamente.

Mesmo sem estarem com problemas de saúde ou doentes, vários Kaingang entrevistados relataram utilizar "remédios do mato" para manterem-se "fortes". Às crianças são administrados "remédios do mato" para "ir formando", "remédios do mato" que servem apenas para crianças e que influenciam na formação de características físicas e de personalidade.

A cosmovisão Kaingang prevê outra dimensão, outro mundo, o "lugar das almas" ou Numbê, que é muito parecido com o território tradicional Kaingang, onde se encontram inúmeras espécies nativas de plantas e animais, lugar em que vivem, "do jeito do índio", de forma tradicional, os espíritos dos seus antepassados, seus familiares e mesmo os animais que já tiveram morte.

É para lá que vão os mortos deste mundo, é um lugar visitado pelos Kaingang mas somente o kujá, o xamã Kaingang, tem proteção para circular entre estes mundos. Aos demais, ir para lá significa ficar vulnerável às enfermidades e em última instância pode levar à morte. Um dos tratamentos de cura do kujá consiste em buscar os espíritos perdidos no Numbê.

Os Kaingang acreditam ser formados por uma complementaridade entre corpo (hã) e espírito (kuprim ou kumbâ) (VEIGA, 1994). O espírito pode deixar o corpo durante o sono, a viagem do espírito ao "mundo dos mortos" torna a pessoa vulnerável às enfermidades, o que acontece principalmente quando se tem saudade, ou quando se pensa muito em alguém que já morreu.

Também potencialmente prejudicial à saúde Kaingang é a presença do waikuprim ou "espírito dos mortos", geralmente o espírito de algum parente, que ao vir à Terra e ficar próximo a alguém, mesmo sem intenção, deixa esta pessoa "fraca", adoece e pode ficar bastante vulnerável à morte terrena.

Os Kaingang não parecem fazer uma oposição radical entre mundo natural, humano e sobrenatural. São, antes, dimensões diferentes que estão em contínua comunicação (VEIGA, 1994, p.153).

\footnotetext{
1 "Remédios do mato" é um termo utilizado por Conceição (1996) e Haverroth (1997) em suas pesquisas na TI Xapecó e também utilizado por alguns informantes indígenas na TI Apucarana.
} 
Neste contexto, inserem-se as questões relativas às enfermidades e à cura Kaingang, como a interpretação que dão às enfermidades, os medicamentos, os tratamentos e práticas de cura, bem como os especialistas procurados.

Este trabalho teve por objetivos revelar aspectos das concepções de saúde e doença expressas pelos habitantes da TI Apucarana, mais especificamente analisar aspectos das práticas de manutenção da saúde, os conhecimentos e a utilização de "remédios do mato". As informações etnográficas aqui apresentadas são frutos de pesquisa de campo realizada na TI Apucarana, localizada na Bacia do rio Tibagi, entre os rios Tibagi, Apucarana e Apucarana grande, limítrofe da cidade de Tamarana, no Paraná, entre os anos de 2010 e 2011. Este estudo constou de pesquisa bibliográfica e pesquisa participante, na qual foi de enorme importância a hospedagem na casa de uma família indígena e o acompanhamento às visitas domiciliares de um agente indígena de saúde (AIS). Foram feitas anotações em diários de campo, além de entrevistas abertas e semi-estruturadas, algumas delas gravadas em áudio e transcritas posteriormente.

\section{Especialistas em cura kaingang}

Por meio da auto-denominação e pelo reconhecimento dos índios da TI Apucarana, foram identificados por esta pesquisa dois especialistas em cura Kaingang, são eles o kujá e o curador.

O kujá é o xamã Kaingang, o especialista que possui o "saber-guiado" ou seja, ele é "guiado" por um espírito-auxiliar, iangré, na busca por algum "remédio do mato" ou na busca pela cura, é o iangré que protege e possibilita a transição do kujá entre este mundo e o Numbê, sendo esta uma especificidade deste especialista (RosA, 2005).

O iangré ou espírito-auxiliar do kujá pode ser o espírito de um animal, de uma planta ou até mesmo um santo do catolicismo popular. Neste último caso, evidencia-se uma ressignificação nas práticas destes especialistas ao incorporarem os santos do catolicismo popular, uma vez que, tradicionalmente, seus guias eram apenas os “seres da floresta”(OLIVEIRA 1996).

É o iangré que ensina ao kujá os rituais de cura e lhe mostra os "remédios do mato" necessários para a cura. É ele também que lhe dá segurança no trânsito entre os dois mundos, o leva e o traz do mundo dos mortos, lugar de onde o kujá resgata espíritos perdidos e assim realiza a cura da pessoa. 
É importante lembrar que a concepção de saúde Kaingang está ligada ao seu conhecimento e à relação que mantém com a natureza, o kujá é quem faz a intermediação entre o doente e os seres da natureza na busca pela cura, sendo muito recorrente a busca dos espíritos das pessoas que têm seus espíritos no Numbê para serem curadas.

O curador, por sua vez, é aquele que possui o "saber não-guiado", ele detém os conhecimentos sobre os "remédios do mato", bem como aqueles utilizados para banhos e garrafadas. Os curadores identificados nesta pesquisa relataram ter preferência pela utilização de plantas provenientes do mato, pois as consideram mais fortes. Mesmo assim, utilizam também plantas colhidas fora da mata, pois, segundo eles, está cada vez mais difícil encontrar algumas espécies de plantas, quando vão à procura de algum venh kagta na mata, acabam tendo que andar o dia todo para encontrar.

Os curadores da TI Apucarana conhecem e utilizam, ainda, diversas espécies de plantas exóticas à sua região, espécimes que adquirem com índios de outras etnias ou mesmo nas casas de comércio de ervas da cidade. Frequentemente, as propriedades curativas destas plantas são reinterpretadas segundo as concepções dos processos de cura Kaingang.

\section{Pluralismo médico na atenção à saúde kaingang}

Para compreender o caminho que o paciente percorre em busca da cura de alguma enfermidade, utilizo do conceito de "itinerário terapêutico" (AugÉ, 1984). 0 itinerário terapêutico compreende um processo que tem seu ponto de partida com a interpretação inicial da enfermidade, em seguida se dão os tratamentos domésticos da enfermidade, a busca ou não pelos especialistas em cura, a escolha de quais especialistas, os tratamentos utilizados, simultaneamente ou não, até a cura ou não da enfermidade.

A interpretação de alguma enfermidade para os Kaingang se dá inicialmente no âmbito familiar, na autoatenção, onde a enfermidade é interpretada e de onde se parte para a busca de algum tratamento e, em alguns casos, a enfermidade é reinterpretada.

[...] las representaciones y prácticas que la población utiliza a nivel de sujeto y grupo social para diagnosticar, explicar, atender, controlar, aliviar, aguantar, curar, solucionar o prevenir los procesos que afectan su salud en términos reales o imaginarios, sin la 
intervención central, directa e intencional de curadores profesionales[...]" (MEnÉnDEZ, 2003 apud SCOPEL, p. 198).

O sistema de saúde Kaingang está em processo de constante transformação, pois resulta de uma dinâmica complexa entre o sistema tradicional de saúde Kaingang, o sistema "médico-religioso" (LANGDon; WiIK, 2010), e o sistema oficial de saúde.

Em outras palavras, na busca pela manutenção da saúde, o índio Kaingang pode, simultaneamente ou não, buscar por meios tradicionais como o atendimento do kujá ou do curador. Pode, ainda, se medicar com os "remédios do mato", procurar o posto de saúde dentro da TI, as farmácias, as diversas religiões dentro e fora da TI e, em casos mais graves, os hospitais das cidades próximas.

Esta distinção entre os diversos sistemas de saúde e especialistas se dá dentro de uma tipologia ideal, uma vez que não podem ser considerados de forma estanque, pois pode-se identificar em um deles, a apropriação de elementos de outros. Desta forma, sistema de atenção à saúde é um conceito que não se constitui em uma realidade para os índios da TI, mas que é utilizado para sistematizar o estudo.

\section{Venh Kagta, "remédios do mato"}

Grande parte dos habitantes da TI Apucarana abordados nesta pesquisa, possui conhecimentos e/ou faz uso dos "remédios do mato", especialmente os anciãos da TI. Além disso, vários indígenas entrevistados disseram que não tomam "remédios do mato" apenas quando estão doentes, mas o fazem constantemente, para se manterem "fortes", para manterem a força (tar).

A grande maioria dos "remédios do mato" registrados na TI Apucarana é originária de plantas, mas existem também "remédios do mato" provenientes de animais e, em menor número, de objetos, como, por exemplo, areia ou pedra que, para os Kaingang, possuem espírito e agem com intencionalidade.

Tradicionalmente os "remédios do mato" só teriam "força" se fossem provenientes da mata fechada, do mato, se, por exemplo, a planta estivesse em um lugar em que passam pessoas ou se fosse uma planta plantada pelo homem, não possuiria propriedades curativas, seria um remédio "fraco".

Das matas tradicionais Kaingang, restaram apenas alguns fragmentos de mata, existindo muitas espécies de plantas e animais já extintos na região. Estes fragmentos são muito importantes e ainda hoje muito utilizados pelos Kaingang pois nestes locais eles vivenciam seus rituais e práticas tradicionais. 
Os Kaingang utilizam os mais variados remédios em conjunto, por exemplo, utilizam medicamentos receitados pelos médicos do posto de saúde juntamente com os "remédios do mato", mas o fazem frequentemente de forma ritual, uma vez que grande parte dos interlocutores indígenas afirma conversar com o medicamento. Quando se pretende a cura por meio de alguma planta, quando colhê-la, usá-la em banho de planta ou sempre que ingerir o chá, deve-se "pedir a cura a ela", "conversar bem com ela".

Portanto, os Kaingang não atribuem a eficácia de um "remédio do mato" somente às suas propriedades farmacológicas, pois esta não depende somente da planta ou do medicamento em si, não se encerra em seu efeito.

A noção do "curar" como uma "forma simbólica" é fundamental para entender a particularidade Kaingáng essencialmente no seu modo de lidar com todos os "seres da natureza" e o poder necessário para que isto ocorra de forma satisfatória (OLIVEIRA, 1996, p. 16).

Haverroth considerou o fato de os Kaingang não possuírem uma visão fragmentada do cosmos, "termos que nomeiam partes de plantas ou objetos a elas relacionados podem ser também rótulos para objetos de outros domínios", (HAVERRoTh,1997, p. 105) o que evidencia a noção de unicidade e interdependência entre os Kaingang e os seres da natureza.

Com o objetivo de analisar os venh kagta utilizados pelos Kaingang da TI Apucarana, será utilizada a classificação utilitária proposta por Haverroth (1997), especificamente no que tange à doença a ser curada.

Pela perspectiva da "doença a ser curada", ficam evidentes as diversas particularidades Kaingang na concepção de saúde e doença. Por exemplo, existem venh kagta utilizados com o propósito de afastar os waikuprim que, como dito anteriormente, causam doenças. Para afastar os espíritos dos mortos, fazem uso da Rabo de Bugio ${ }^{2} \mathrm{e}$ da Kóveju, plantas bastante utilizadas para fins medicinais.

A Rabo de Bugio também é utilizada pelos Kaingang para não se perderem no mato. Existem outras, como o Cipó Cruz, que desorienta a pessoa que passar por debaixo dele, exceto aquela que estiver carregando consigo um pedaço do cipó Rabo de Bugio.

\footnotetext{
${ }^{2}$ As plantas aqui citadas levam seus nomes populares, transcritas da forma como foram citadas ou soletradas pelos informantes indígenas.
} 
O susto é outro exemplo de "doença a ser curada" e, assim como em outros exemplos, revela uma concepção bastante distinta daquela da medicina oficial. Do susto, decorre a perda do espírito, acredita-se que o espírito assustado, geralmente de crianças, sai do corpo terreno e se perde no Numbê. Existem "remédios do mato" para acalmar a criança ou preveni-la do susto, se o espírito sair do corpo, no entanto, somente um kujá poderá trazê-lo de volta.

Há relatos, registrados nesta pesquisa, de crianças que se assustaram quando estavam atravessando um rio, ou quando estavam andando na mata ou que se assustaram com trovões. Em todos estes casos previstos "remédios do mato" e regras de comportamento para as devidas precauções e providências.

[...], a interpretação de uma desordem corporal, biológica nas sociedades tradicionais faz-se sempre em referência às regras sociais, culturais; em poucas palavras, a uma organização social, religiosa ou simbólica específica (BUCHILLET, p. 26).

Esta pesquisa identificou que os Kaingang consideram também a nominação dos recém-nascidos como remédios, pois acreditam que estes atuam na proteção deles, ou seja, seus nomes influenciam diretamente em sua saúde, protegem-nos de doenças e de espíritos.

O nome segundo os curadores atua como um fortalecimento, uma proteção - tanto na ocasião do nascimento (para o recém-nascido) como no decorrer das diferentes etapas do ciclo de vida. Desse modo, ao fazermos uma analogia, o nome atuaria como algo constitutivo que protege, uma substância (ou algo que se substancializa) no corpóreo, [...] (OLIVEIRA, 1996, p. 45).

Podem ser citados alguns exemplos da nominação utilizados como proteção registrados na TI, como Tãká, que protege de sustos e de waikuprim. Kaafár é o nome de um menino e significa casca de árvore, uma proteção contra os espíritos, assim como a casca é a proteção da árvore. “(...) a palavra pó (pedra) é utilizada como nome masculino (Pó ronga, Pó xí) para prevenir doenças, "pois é dura, não acaba mais, não termina" (SILVA, 2002, p. 206).

Outra perspectiva da utilização de "remédios do mato" pelos Kaingang da TI Apucarana, se dá pelo "registro das causas" e do "registro dos efeitos" das enfermidades, propostos por Buchillet (1991). Por esta perspectiva, a utilização de medicamentos ocorre de duas formas, pela ação nas causas das enfermidades, "registro das causas", e nos efeitos das enfermidades, "registro dos efeitos". 
Considerando esta perspectiva apontada por Buchillet, esta pesquisa revelou que, em diversos casos, os medicamentos do posto de saúde são utilizados pelos Kaingang da TI Apucarana de forma a agir nos efeitos da enfermidade, ao passo que, em outros casos, os "remédios do mato" e os tratamentos dos kujás e do curador irão agir nas causas destas enfermidades. Isto evidencia a importância e a centralidade, nos processos de cura, destes especialistas dentro do sistema de atenção à saúde Kaingang.

\section{Venh Kagta e a cura por analogia}

Esta pesquisa constatou a recorrência da utilização de "remédios do mato" na TI Apucarana que operam por meio de uma relação de analogia entre a pessoa e o medicamento, quer seja planta, animal ou objeto. Ou seja, as características observáveis destes medicamentos são transmitidas ao homem, um exemplo disto se dá na utilização da planta "vassourinha" que, por ser difícil de "arrancar" manualmente da terra, é usada em banho para fortalecer os cabelos, tornando-os difíceis de "arrancar" ou de cair, assim como a planta.

Outro exemplo registrado é a utilização de uma espécie de samambaia, abundante na TI, para banhar os recém-nascidos. Devido às folhas nascerem "enroladinhas", a criança ficará com que seu cabelo bastante enrolado, bem crespo, como o observado nas folhas novas da planta.

A planta "pau de anta" passa por uma relação de analogia que envolve a imitação do comportamento de um animal nativo do território Kaingang, a anta. 0 Kaingang copia o comportamento deste animal, que utiliza a planta para curar suas feridas. A anta quando ferida morde o caule da árvore "pau de anta" e esfrega a sua ferida na ferida da árvore.

Além disso, há diversos "remédios do mato" que seguem o princípio da analogia e que são utilizados para as crianças. Foram registrados venh kagta que agem sobre a destreza, a memória, as características físicas, a personalidade, entre outros.

É o caso da planta "unha-de-gato" que, se utilizada adequadamente em banho ritual, forma uma criança que agarra bem, "agarra em uma briga e não solta" e é utilizado também para que a criança suba com agilidade em árvores, uma vez que unha-de-gato é uma trepadeira.

Por exemplo, a árvore denominada ken ta iú (açoita cavalo) é concebida como remédio porque "não pega doença", e, quando cortada, brota rapidamente, "não se termina". Já a figueira (ken ven fi), por "espremer, abafar, matar e tomar o lugar de outras árvores", é 
percebida como "remédio brabo", isto é, para "ficar brabo, lutar".[...] as "pedras d água", alisadas pela ação da corrente, são usadas como preventivo contra rugas: 'fica velho, mas fica sempre que parece novo". Pequenos animaizinhos que se agitam rapidamente sobre as águas paradas (uoï-uoi) são indicados para quem quer ter destreza na luta contra inimigos, transmitindo para o paciente o poder de defesa contra seus golpes e flechas (SILVA, 2002, p. 206-207).

Outra prática que segue este princípio de ação por analogia, e que foi apontada por diversos informantes, é a de enterrar do umbigo do recém-nascido, uma prática muito importante com efeito esperado na formação do corpo. Em rituais específicos, eles são enterrados nos pés de árvores (Kaa) ou mesmo são colocados dentro de buracos na árvore que, desta forma, influenciará as características físicas e comportamentais daquele indivíduo, de acordo com as características da árvore escolhida. É preciso escolher bem a árvore, pois se a árvore adoecer, isto significará o adoecimento da pessoa que tem seu umbigo ali enterrado.

\section{Considerações Finais}

Esta pesquisa propôs-se a revelar aspectos atuais do sistema de atenção à saúde Kaingang na TI Apucarana, enfocando os conhecimentos e práticas dos seus habitantes em relação à cura, principalmente, no que se refere aos "remédios do mato", amplamente utilizados por especialistas e "não-especialistas" em cura na TI.

Buscou-se estabelecer as especificidades da concepção Kaingang dos processos de adoecer e curar, em que a noção de força, tar, ou o estar forte é essencial na prevenção de enfermidades e também na cura.

Este trabalho também buscou apontar aspectos das causas das enfermidades, como são interpretadas e o que são consideradas enfermidades para os Kaingang, revelando aspectos de uma cultura particular que, com a presença das inúmeras formas de atenção à saúde na TI, são reinventadas e reinterpretadas pelos Kaingang através, principalmente, de sua cosmovisão.

A análise sobre os venh kagta permitiu também um olhar sobre a relação dos Kaingang com o seu meio ambiente e com os seres que nele habitam e como, utilizando-se dos "remédios do mato", estes agem por um princípio particular, não considerado válido pela biomedicina, em que as características físicas observáveis de um "remédio do mato" é transmitido ao Kaingang, para a cura ou para a formação do corpo e de sua personalidade. 
Considerando os diversos sistemas de atenção à saúde Kaingang, este trabalho pretendeu demonstrar o caráter dinâmico da cultura Kaingang ligada às suas práticas de cura, devido a coexistência das diversas formas de atenção e dos sentidos que os Kaingang atribuem às diversas formas de curar.

Contrário à ideia de "assimilação" cultural de práticas não indígenas de atenção à saúde e de "perda cultural" das práticas tradicionais Kaingang na manutenção da saúde, este artigo pretendeu evidenciar a ressignificação das práticas de manutenção à saúde dos Kaingang, principalmente, por meio de sua visão de cosmos na relação que mantêm com a natureza.

\section{Referências}

BAInes, S. (2004). "Antropologia do Desenvolvimento e a questão das sociedades indígenas". Revista Anthropológicas, ano 8, volume 15.

Buchillet, D. (1991).(org.) Medicinas Tradicionais e Medicina Ocidental na Amazônia. Belém: CNPq/SCT/PR/CEJUP/UEP.

CRÉPEAU, R. (2002)."A prática do xamanismo entre os Kaingáng do Brasil Meridional: uma breve comparação com o xamanismo Bororo". In: Horizontes Antropológicos, Porto Alegre, ano 8, n.18.

(2006). “Os Kamé vão sempre primeiro: Dualismo social e reciprocidade entre os Kaingang”. Anuário Antropológico. Rio de Janeiro: Tempo Brasileiro.

Descola, P. (1998). "Estrutura ou sentimento: A relação com o animal na Amazônia”. Mana, Rio de Janeiro, v.4, n.1, p.23-45.

DiEHL, E. (2001). Entendimentos, práticas e contextos sociopolíticos do uso dos medicamentos entre os Kaingang (Terra Indígena Xapecó, SC. Brasil). Dissertação de doutorado. Rio de Janeiro: ENSP/FIOCRUZ.

Haverroth, M. K. (1997). Um estudo etnobotânico: O Uso e a Classificação das Plantas na Área Indígena Xapecó (Oeste de SC). Dissertação de Mestrado. Florianópolis: PPGAS/ UFSC.

LANGDON, E. J., WIIK, F. B. (2010). “Antropologia, saúde e doença: uma introdução ao conceito de cultura aplicado às ciências da saúde". Revista Latino-Am. Enfermagem [Internet]. Mai-jun.

Nimuendajú, C. U. (1993). Etnografia e Indigenismo: Sobre os Kaingang, os Ofaié-Xavante e os Índios do Paraná. Campinas: Ed. da Unicamp. 
Oliveira, M. C. (1996). Os especialistas Kaingáng e os seres da natureza: curadoria da aldeia Xapecó - Oeste de Santa Catarina. Florianópolis: FCC.

. (2000). "Dinâmica do sistema cultural de saúde Kaingang - aldeia Xapecó, Santa Catarina”. In: Uri e Wãxi. Estudos Interdisciplinares dos Kaingang. Londrina: EDUEL.

Rosa, R. R. da. (2005). Os Kujá são diferentes: Um estudo etnológico do complexo xamânico dos Kaingang da terra indígena Votouro. Tese de Doutorado, Programa de Pós-Graduação em Antropologia Social. Instituto de Filosofia e Ciências Humanas. Porto Alegre: Universidade Federal do Rio Grande do Sul.

Scopel, D., DiAs-Scopel, R. P. (2011). “Autoatenção e Intermedicalidade: práticas e espaços de negociação no campo religioso Munduruku". In: Reunião de Antropologia do Mercosul, n.IX. Curitiba.

SiLva, S. B. (2002). "Dualismo e Cosmologia Kaingang: O Xamã e o domínio da floresta”. Horizontes Antropológicos, Porto Alegre, ano 8, n.18. Divulgação Cultural, Ano 20/64: 21-31. Blumenau, SC.

Tommasino, K. (2000). “Território e territorialidade Kaingang”. In: Tommasino, K.; MotA, L. T.; NoElli, F. S. (Orgs.). Uri e Wãxi: estudos Interdisciplinares dos Kaingang. Londrina: Editora da UEL.

. (2002). "A ecologia dos kaingang da bacia do tibagi". In: A Bacia do Rio Tibagi / MEDRI, Moacyr E. [et al.], editores. Londrina, PR.

(2004). "Homem e natureza na ecologia dos Kaingang da bacia do Tibagi". In: TOMMASINO, Kimiye, MOTA, Lucio Tadeu. \& NOELLI, Francisco Silva (eds.). Novas contribuições aos estudos interdisciplinares dos Kaingang: 145-198. Londrina, PR: EDUEL.

Veiga, J. (1994). Organização Social e Cosmovisão Kaingang: uma introdução ao parentesco, casamento e nominação em uma sociedade Jê Meridional. Dissertação de Mestrado. Campinas, UNICAMP: Programa de Pós-Graduação em Antropologia Social.

Recebido em abril/2012

Aprovado em junho/2012 